\title{
A bundled approach to care: reducing the incidence of postoperative pneumonia in patients undergoing hepatectomy and Whipple procedures
}

\author{
Gifty Mahama, MN \\ Laavanyah Vigneswaran, MPH \\ Alice Silva, MPH \\ Azusa Maeda, PhD \\ Dalton-Grant Davis, RN \\ Lenore Thomas, RN, BSc \\ Beverly Barretto, RN \\ Sandra Weller, RN \\ Allan Okrainec, MD, MHPE \\ Joseph Gajasan, MN, MBA \\ Timothy Jackson, MD, MPH
}

The material discussed in this manuscript was previously presented at the American College of Surgeons Quality and Safety Conference in Florida, United States, July 2018.

\section{Accepted Feb. 25, 2020}

\section{Correspondence to:}

T.D. Jackson

Toronto Western Hospital

University Health Network

399 Bathurst St, Room 8MP-322

Toronto ON M5T 2S8

timothy.jackson@uhn.ca

DOI: $10.1503 /$ cjs. 016818

\begin{abstract}
SUMmaRY
Postoperative occurrence of pneumonia can increase lengths of stay, risk of morbidity and death and health care costs. At Toronto General Hospital, we identified a high incidence of postoperative pneumonia in patients undergoing hepatectomy and Whipple procedures in 2016. To reduce the incidence of postoperative pneumonia, we implemented an evidence-based bundle approach in 2017. The bundle included the following components: oral care, incentive spirometry, coughing and deep breathing, physical activity, elevation of the head of the bed, and patient and family education. In addition to the bundle components, we provided staff education and created patient education and monitoring tools to ensure competency and compliance with the bundle components. Data collected as part of the National Surgical Quality Improvement Program were reviewed to monitor progress. In this article, we discuss our approach, aimed to reduce the incidence of postoperative pneumonia and associated health care costs in the general surgery population.
\end{abstract}

D ostoperative pneumonia is a common hospital-acquired infection associated with substantial morbidity and death. Although most approaches focus on the prevention of ventilator-associated pneumonia (VAP), ${ }^{1}$ only $39.1 \%$ of postoperative pneumonia events are associated with the use of a ventilator. ${ }^{2}$ Few studies to date describe pneumonia prevention strategies in non-mechanically ventilated patients. ${ }^{3,4}$

Toronto General Hospital is a large academic hospital with 457 beds. Data collected through the American College of Surgeons National Surgical Quality Improvement Program (ACS NSQIP) at our institution revealed a much higher than expected rate of non-VAP in patients undergoing hepatectomy and Whipple procedures since 2014 compared with other NSQIP hospitals. Based on these data, a multidisciplinary working group was created to implement a quality-improvement initiative in our unit.

\section{OUR APPROACH}

\section{Bundle components}

We adopted a bundle approach called ICOUGH ${ }^{4}$ to all patients undergoing hepatectomy and Whipple procedures, beginning in January 2017. The bundle approach was selected as it is more effective than a singlemeasure approach. ${ }^{4}$

Components of the bundle include the following: oral care (brushing teeth and tongue 3 times per day), incentive spirometry ( 5 times every 2 hours), coughing and deep breathing ( 3 times every 2 hours), physical activity ( 2 times per shift), elevation of the head of the bed (at least $30^{\circ}$ at all times, and at least $45^{\circ}$ during meals; $90^{\circ}$ if patient is at high risk of 
aspiration), and patient and family education on pneumonia prevention and bundle components.

We created 3 specific tools in conjunction with the bundle, including a postoperative pathway to guide clinical care, a patient informational pamphlet provided upon admission to the inpatient unit and a tracking sheet to monitor compliance with the bundle components. Packages containing a tube of toothpaste, toothbrush, incentive spirometer and a bottle of mouthwash were prepared.

\section{Staff education}

Unit staff were trained on the bundle components, and daily safety huddles were used as an opportunity to remind staff about required documentation. Two nurses were designated to serve as unit champions. Their responsibilities included educating relief staff, flagging charts, providing tracking tools to the nursing staff, preparing supplies and assisting with document retrieval at the time of discharge.

\section{Clinical pathway}

The clinical pathway (Fig. 1) was initiated with the identification of hepatectomy and Whipple patients, flagging of charts and dissemination of the bundle to the assigned registered nurse. The assigned registered nurse provided education and supplies to each patient and ensured competency through teach-back, namely having the patient explain concepts back to the teacher. In addition to documentation completed by the nursing staff, patients also tracked their completed components on a separate form. Patients initially recovered in the acute care unit before being downgraded to a ward room (step down), and were followed by physiotherapy and occupational therapy staff who assessed patients for their readiness to participate in the early mobility program. This program engaged nursing and physiotherapy student volunteers to assist patients with the bundle components. Prior to discharge, all patients were seen by a discharge navigator who taught them about continuing pneumonia prevention at home. Patients also received a follow-up call from the navigator to ensure that there were no further postoperative complications.

\section{Evaluation}

An internal ACS NSQIP database was used to obtain patient baseline characteristics and postoperative pneumonia data. Data on hospital costs were

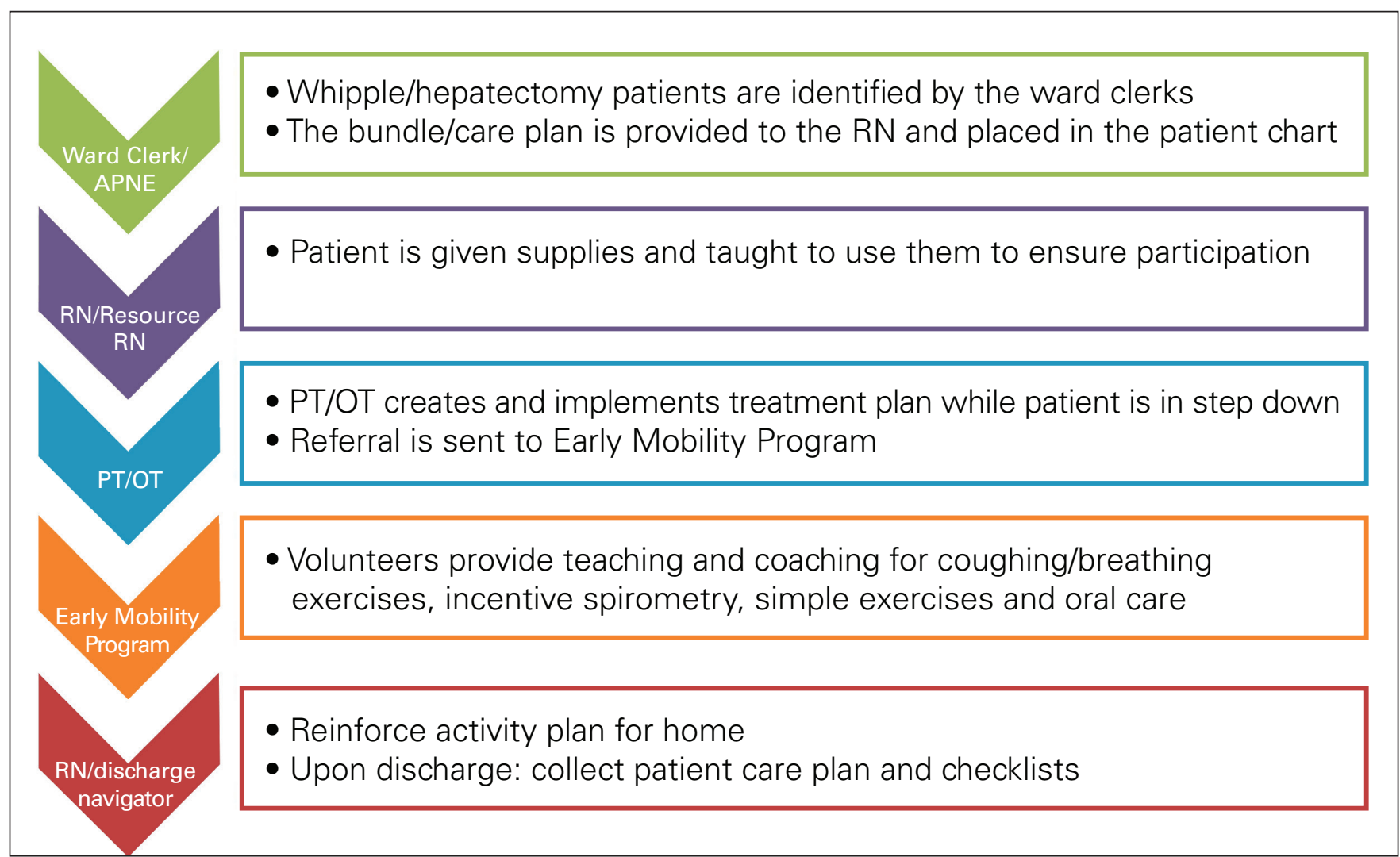

Fig. 1. The multidisciplinary clinical pathway used to guide clinical care of patients undergoing hepatectomy or Whipple procedures. $\mathrm{APNE}=$ advance practice nurse educator $; \mathrm{OT}=$ occupational therapist; $\mathrm{PT}=$ physiotherapist; $\mathrm{RN}=$ registered nurse . 
obtained from our institutional Case Costing Department. We used the two-tailed Student $t$ test to compare continuous variables, and the $\chi^{2}$ test to compare categorical variables.

\section{RESULTS}

The pneumonia prevention bundle was implemented with 266 patients who underwent hepatectomy and Whipple procedures and were admitted to our general surgery inpatient unit in 2017. Apart from the proportion of smokers among patients undergoing Whipple procedures, there were no significant differences in the baseline characteristics of patients in 2016 and 2017 (Table 1). Most patients were rated at an American Society of Anesthesiology class $\geq 3$, which is a known risk factor for postoperative pneumonia. ${ }^{5}$

Compared with patients who did not develop any complications, those who underwent hepatectomy and subsequently developed postoperative pneumonia during their hospital stay had a significantly longer length of stay (6.30 v. 14.74 days) and hospital cost (\$17492 v. $\$ 37403$ ) (Table 2). Similar results were obtained for those who underwent Whipple procedures. After implementation of the ICOUGH bundle in 2017, postoperative pneumonia rates for hepatectomy and Whipple procedures reduced significantly compared to 2016 rates, from $27.2 \%$ to $15.2 \%(p=0.010)$ and from
$35.6 \%$ to $15.8 \%$ ( $p=0.001$ ), respectively (Fig. 2). Overall, there was a significant reduction in the total cost of hepatectomy and Whipple procedures, from \$27468 in 2016 to $\$ 22217$ in $2017(p=0.040)$ (Table 3).

\section{Discussion}

We showed that implementation of our approach was feasible and effective in reducing the incidence of postoperative pneumonia and associated health care use. We also identified factors that are critical to implementing this bundle effectively as a standard of care.

First, implementation required the education of external staff. The relief staff (external to our inpatient unit) had no prior knowledge or education of the ICOUGH bundle and its requirements. For the purpose of maintaining and ensuring consistency in practice, 2 unit champions (modified registered nurses) acted as primary resources for relief staff. They provided oneon-one education about the bundle and assisted with the bundle components and documentation.

A second critical factor was preoperative patient education. Patients reported that they found it difficult to absorb and retain information postsurgery as they were simultaneously facing other challenges and competing information from other services. Patients also identified that it would have been beneficial to practise with some of the equipment (e.g., incentive spirometry) and to

Table 1. Characteristics of patients who underwent hepatectomy and Whipple procedures in 2016 and 2017*

\begin{tabular}{|c|c|c|c|c|c|c|}
\hline \multirow[b]{2}{*}{ Characteristic } & \multicolumn{3}{|c|}{ Hepatectomy, no. (\%)† } & \multicolumn{3}{|c|}{ Whipple, no. (\%)† } \\
\hline & $\begin{array}{c}2016 \\
n=147\end{array}$ & $\begin{array}{c}2017 \\
n=165\end{array}$ & $p$ value & $\begin{array}{c}2016 \\
n=104\end{array}$ & $\begin{array}{c}2017 \\
n=101\end{array}$ & $p$ value \\
\hline Age, $y r$, mean \pm SD & $61.0 \pm 12.4$ & $60.0 \pm 14.3$ & 0.67 & $65.0 \pm 12.0$ & $65.3 \pm 10.1$ & 0.95 \\
\hline Sex, male & $90(61.4)$ & $101(61.2)$ & 0.97 & $50(48.5)$ & $51(50.5)$ & 0.78 \\
\hline $\mathrm{BMI}$, mean $\pm \mathrm{SD}$ & $26.4 \pm 5.0$ & $26.3 \pm 4.7$ & 0.98 & $26.3 \pm 4.6$ & $26.7 \pm 5.2$ & 0.60 \\
\hline Smoker & $26(17.7)$ & $25(15.2)$ & 0.55 & 19 (18.3) & 32 (31.7) & 0.03 \\
\hline ASA class $\geq 3$ & $130(88.4)$ & 155 (93.9) & 0.09 & $101(97.1)$ & $95(94.1)$ & 0.30 \\
\hline \multicolumn{7}{|c|}{$\begin{array}{l}\text { ASA = American Society of Anesthesiology physical status classification; BMI }=\text { body mass index; } S D=\text { standard deviation. } \\
{ }^{*} \text { The ICOUGH bundle was implemented in January 2017. A 2-tailed Student } t \text { test was used to compare continuous variables, and a } \chi^{2} \text { test was used to } \\
\text { compare categorical variables. } \\
\text { tUnless indicated otherwise. }\end{array}$} \\
\hline
\end{tabular}

Table 2. Length of stay and hospital cost for patients with and without postoperative pneumonia during their hospital stay following hepactomy and Whipple procedures in 2016 and 2017

\begin{tabular}{|c|c|c|c|c|c|c|}
\hline \multirow[b]{2}{*}{ Variable } & \multicolumn{3}{|c|}{ Hepatectomy } & \multicolumn{3}{|c|}{ Whipple } \\
\hline & $\begin{array}{c}\text { No complication } \\
n=247\end{array}$ & $\begin{array}{l}\text { Postoperative pneumonia } \\
\qquad n=65\end{array}$ & $p$ value & $\begin{array}{c}\text { No complication } \\
n=152\end{array}$ & $\begin{array}{l}\text { Postoperative pneumonia } \\
\qquad n=53\end{array}$ & $p$ value \\
\hline $\begin{array}{l}\text { Length of stay, } \\
\text { days, mean } \\
(95 \% \mathrm{Cl})\end{array}$ & $6.30(5.74-6.86)$ & $14.74(11.62-17.85)$ & $<0.001$ & $11.65(9.51-13.79)$ & $19.84(11.52-28.15)$ & 0.008 \\
\hline $\begin{array}{l}\text { Total cost, mean, } \\
95 \% \mathrm{Cl})^{*}\end{array}$ & $\begin{array}{c}\$ 17492 \\
(\$ 15643-\$ 19340)\end{array}$ & $\begin{array}{c}\$ 37403 \\
(\$ 28402-\$ 46404)\end{array}$ & $<0.001$ & $\begin{array}{c}\$ 28894 \\
(\$ 21977-\$ 35811)\end{array}$ & $\begin{array}{c}\$ 44775 \\
(\$ 25974-\$ 63577)\end{array}$ & 0.062 \\
\hline
\end{tabular}




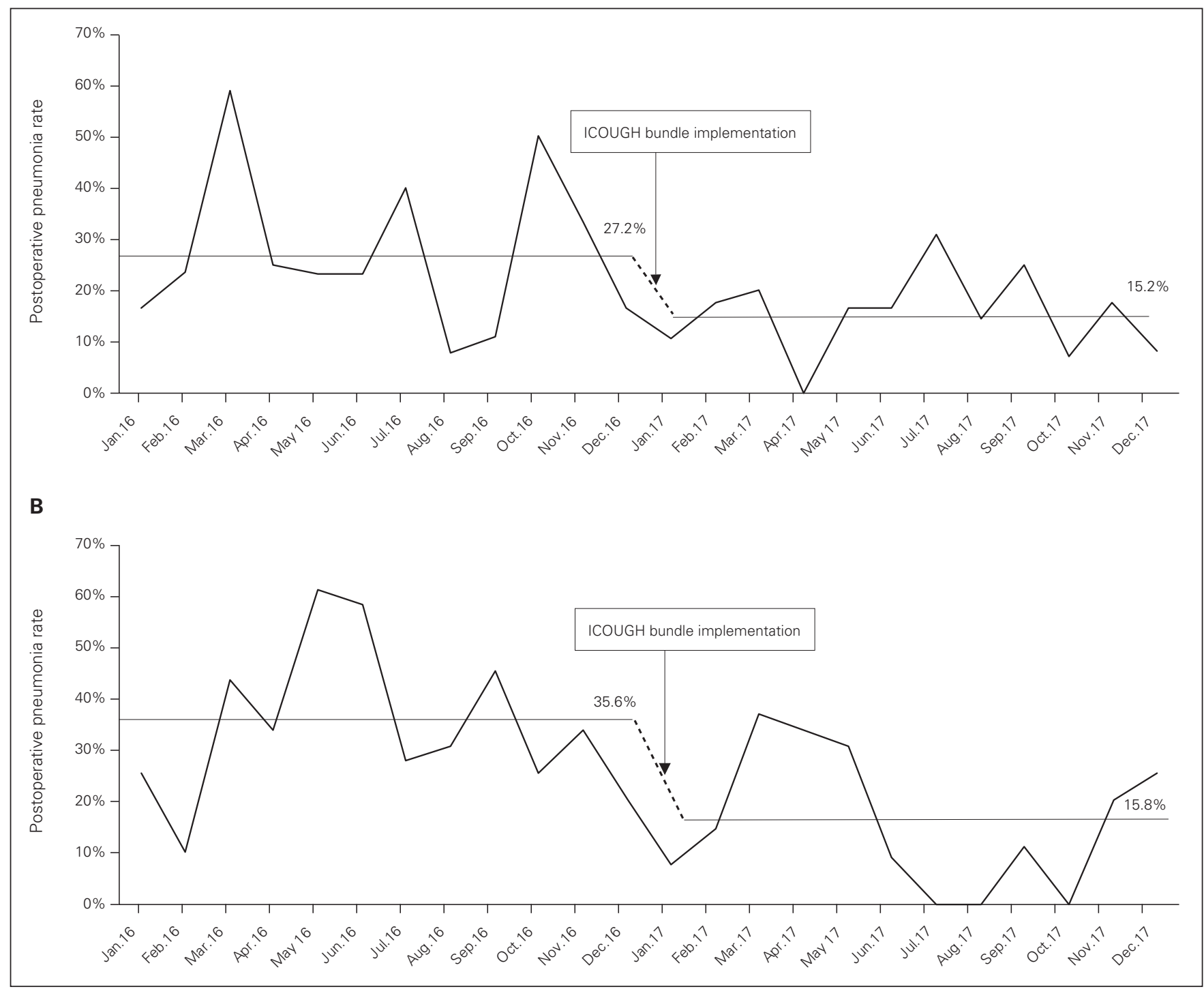

Fig. 2. Postoperative pneumonia rates for patients who underwent A) hepatectomy and B) Whipple procedures in 2016 and 2017.

Table 3. Length of hospital stay and hospital cost for all hepatectomy and Whipple procedures performed in 2016 and 2017

\begin{tabular}{|c|c|c|c|c|c|c|c|c|c|}
\hline Variable & \multicolumn{3}{|c|}{ Hepatectomy } & \multicolumn{3}{|c|}{ Whipple } & \multicolumn{3}{|c|}{ Hepatectomy + Whipple } \\
\hline $\begin{array}{l}\text { Total cost, } \\
\text { mean }(95 \% \mathrm{Cl})^{*}\end{array}$ & $\begin{array}{c}\$ 22583 \\
(\$ 19591- \\
\$ 25575)\end{array}$ & $\begin{array}{c}\$ 19785 \\
(\$ 17044- \\
\$ 22526)\end{array}$ & 0.17 & $\begin{array}{c}\$ 34519 \\
(\$ 24787- \\
\$ 44251)\end{array}$ & $\begin{array}{c}\$ 26235 \\
(\$ 22917- \\
\$ 29553)\end{array}$ & 0.11 & $\begin{array}{c}\$ 27468 \\
(\$ 23126- \\
\$ 31810)\end{array}$ & $\begin{array}{c}\$ 22217 \\
(\$ 20129- \\
\$ 24305)\end{array}$ & 0.04 \\
\hline
\end{tabular}

have clinical guidance to help them work through exercises outlined in the bundle before the surgery. It would be beneficial to introduce the bundle at the preoperative phase of the surgical pathway to further support patient education, active participation and completion of bundle components.

\section{Conclusion}

Strategies used in this program are easily transferable to other units. Staff education, patient engagement and availability of a multidisciplinary team are critical to ensure sustainability and adaptation of this program. 
Acknowledgements: The authors thank MaryAnn Neary, the entire 9ES General Surgery Nursing Unit, the Early Mobility Program and the Allied Health Care Team at Toronto General Hospital, University Health Network.

Affiliations: From the Division of General Surgery, University Health Network, Toronto, Ont. (Mahama, Vigneswaran, Maeda, Davis, Thomas, Barretto, Weller, Okrainec, Gajasan, Jackson); the Infection Prevention and Control, University Health Network, Toronto, Ont. (Silva); and the Department of Surgery, University of Toronto, Toronto, Ont. (Okrainec, Jackson).

Competing interests: None declared.

Contributors: All authors contributed substantially to the conception, writing and revision of this article and approved the final version for publication.

Content licence: This is an Open Access article distributed in accordance with the terms of the Creative Commons Attribution (CC BYNC-ND 4.0) licence, which permits use, distribution and reproduction in any medium, provided that the original publication is properly cited, the use is noncommercial (i.e., research or educational use), and no modifications or adaptations are made. See: https://creativecommons. org/licenses/by-nc-nd/4.0/

\section{References}

1. Bouadma L, Wolff M, Lucet J-C. Ventilator-associated pneumonia and its prevention. Curr Opin Infect Dis 2012;25:395-404.

2. Magill SS, Edwards JR, Bamberg W, et al. Multistate pointprevalence survey of health care-associated infections. $N$ Engl 7 Med 2014;370:1198-208.

3. Kazaure HS, Martin M, Yoon JK, et al. Long-term results of a postoperative pneumonia prevention program for the inpatient surgical ward. FAMA Surg 2014;149:914-8.

4. Cassidy MR, Rosenkranz P, McCabe K, et al. I COUGH: reducing postoperative pulmonary complications with a multidisciplinary patient care program. FAMA Surg 2013;148:740-5.

5. Chughtai M, Gwam CU, Mohamed N, et al. The epidemiology and risk factors for postoperative pneumonia. 7 Clin Med Res 2017; 9:466-75. 